\title{
The beneficial role of left ventricular assist device destination therapy in the reversal of contraindications to cardiac transplantation
}

\author{
Cliff K. Choong, FRACS, ${ }^{a}$ Michael K. Pasque, MD, ${ }^{a}$ Kim Shelton, RN, ${ }^{b}$ \\ Beth Kehoe-Huck, RN, ${ }^{\mathrm{b}}$ Gregory A. Ewald, MD, ${ }^{\mathrm{b}}$ Douglas Horstmanshof, MD, ${ }^{\mathrm{b}}$ and \\ Nader Moazami, MD, ${ }^{\text {a }}$ St Louis, Mo
}

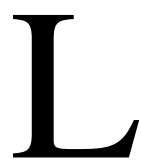
eft ventricular assist devices (LVADs) are increasingly used as destination therapy for patients with end-stage heart failure who are unsuitable for cardiac transplantation. ${ }^{1-3}$ There are few data regarding patients placed on LVADs intended for destination therapy whose improvement eventually allows for listing for cardiac transplantation. We report our experience with such a group of patients.

\section{Clinical Summary}

Between January 2000 and September 2004, 15 patients received destination LVAD therapy in our institution. Nine patients had received the Novacor device as part of the INTrEPID (Investigation of Non-Transplant-Eligible Patients who are Inotrope Dependent) trial, and 6 had received the HeartMate XVE device (Thoratec Corporation) after US Food and Drug Administration approval was granted for destination therapy. From this group, 6 patients were reevaluated and listed for transplantation. The mean age was 52 years (range, 31-66 years). The cause of the underlying cardiomyopathy was ischemic in 4 patients, idiopathic in 1 patient, and adriamycin-induced heart failure in 1 patient. Contraindications for cardiac transplantation before LVAD destination therapy were irreversible severe pulmonary hypertension in 5 patients, 2 of whom also had concomitant renal insufficiency and 1 of whom had a recent history of treated endometrial cancer (Table 1). After LVAD implantations, significant reduction in pulmonary arterial pressure, pulmonary vascular resistance, and renal function was seen in these patients (Table 2). Heart transplantation was initially contraindicated in another patient because of psychosocial history and poor compliance. The mean duration of LVAD support until listing among the 6 patients was 243 days (range, 88-684 days). Four patients have undergone transplantation and are alive at a mean duration of 33 months (range, 8-55 months; Table 1). One patient is still on the waiting list, and 1 died from a hemorrhagic

From the Division of Cardiothoracic Surgery ${ }^{\mathrm{a}}$ and the Division of Cardiology, ${ }^{\mathrm{b}}$ Washington University School of Medicine, St Louis, Mo.

Received for publication Dec 2, 2004; revisions received Dec 28, 2004; accepted for publication Feb 10, 2005.

Address for reprints: Nader Moazami, MD, Division of Cardiothoracic Surgery, Washington University School of Medicine, Suite 3108, Queeny Tower, One Barnes-Jewish Hospital Plaza, St Louis, MO 63110 (E-mail: moazamin@msnotes.wustl.edu).

J Thorac Cardiovasc Surg 2005;130:879-80

$0022-5223 / \$ 30.00$

Copyright $\odot 2005$ by The American Association for Thoracic Surgery

doi:10.1016/j.jtcvs.2005.02.014 cerebrovascular accident before undergoing transplantation. In the one patient with can-

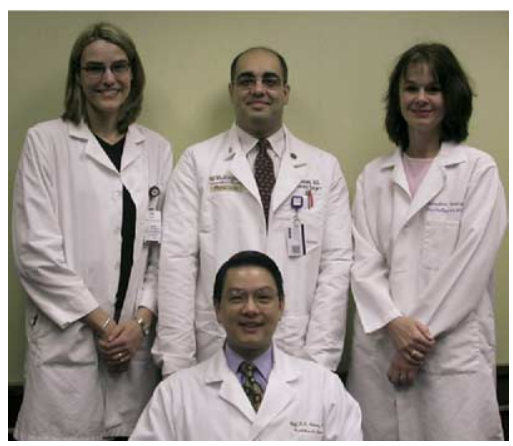

Front: Choong; back, left to right: Kehoe-Huck, Mouzami, Shelton cer, there has been no evidence of recurrence. None of the patients who underwent transplantation with previous pulmonary hypertension had significant perioperative right ventricular dysfunction.

The remaining 9 patients with LVAD destination therapy were not offered heart transplantation because of either the presence of ongoing contraindications to heart transplantation or perioperative death after LVAD implantation. The contraindications to heart transplantation in these 9 patients were significant comorbidity in 3 patients, advanced age in combination with significant comorbidity in 3 patients, and malignancy in 2 patients. At a mean follow-up of 200 days (range, 1-1095 days), 5 patients were deceased, whereas the remaining patients were still alive. The causes of death in the 5 patients were multiorgan failure in 3 patients, traumatic hemorrhagic cerebrovascular accident after a motor vehicle accident in 1 patient, and intraoperative death in 1 patient.

\section{Discussion}

Cardiac transplantation has been the conventional surgical treatment for patients with late-stage heart failure who are not amenable to other cardiac surgical therapy, such as coronary artery bypass or valvular surgery. ${ }^{4}$ For patients with pulmonary hypertension, eligibility for listing for cardiac transplantation depends on the demonstration of reversibility of the high pulmonary vascular resistance with vasodilators, such as nitroprusside, nitroglycerin, prostacyclin, or inhaled nitric oxide. In general, it is preferable to demonstrate a reduction of pulmonary vascular resistance to 4 Wood units or less before patients are considered suitable for transplantation. In the setting of end-stage heart failure, sometimes it can be difficult to establish the reversibility of pulmonary hypertension. Pharmacologic options to unload the left heart are limited, and uptitration of vasodilator drugs is associated with systemic hypotension. Patients found to have severe irreversible pulmonary hypertension are therefore precluded from consideration for cardiac transplantation or LVAD therapy as a bridge to transplantation.

The REMATCH trial was a landmark prospective trial in patients ineligible for heart transplantation that demonstrated the survival advantage of patients treated with an LVAD compared with those receiving optimal medical therapy. ${ }^{1}$ The results of this study provided the major impetus for the US Food and Drug Administration to grant approval in November 2002 for the use of the HeartMate device as destination therapy for patients ineligible 
TABLE 1. Initial contraindications to cardiac transplantation and outcomes after intended LVAD destination therapy

\begin{tabular}{|c|c|c|}
\hline Patient no. & Contraindications to cardiac transplantation & Outcomes after intended LVAD destination therapy \\
\hline 1 & Pulmonary hypertension and renal insufficiency & $\begin{array}{l}\text { Resolution of pulmonary hypertension and renal insufficiency, } \\
\text { followed by successful cardiac transplantation }\end{array}$ \\
\hline 2 & Pulmonary hypertension and renal insufficiency & $\begin{array}{l}\text { Resolution of pulmonary hypertension and renal insufficiency; } \\
\text { death caused by cerebrovascular accident }\end{array}$ \\
\hline 3 & $\begin{array}{l}\text { Pulmonary hypertension and treated } \\
\text { endometrial carcinoma }\end{array}$ & $\begin{array}{l}\text { Resolution of pulmonary hypertension and no recurrence of } \\
\text { carcinoma, followed by successful cardiac transplantation }\end{array}$ \\
\hline 4 & Pulmonary hypertension & $\begin{array}{l}\text { Resolution of pulmonary hypertension, followed by successful } \\
\text { cardiac transplantation }\end{array}$ \\
\hline 5 & Pulmonary hypertension & $\begin{array}{l}\text { Resolution of pulmonary hypertension; listed for cardiac } \\
\text { transplantation }\end{array}$ \\
\hline 6 & $\begin{array}{l}\text { Psychosocial history: smoker, poor compliance, } \\
\text { and poor social support }\end{array}$ & $\begin{array}{l}\text { Improvement in compliance, developed good social support, } \\
\text { and ceased smoking; successful cardiac transplantation }\end{array}$ \\
\hline
\end{tabular}

LVAD, Left ventricular assist device.

for cardiac transplantation. ${ }^{2,3}$ Despite a rapid proliferation of centers recognized by the Centers for Medicare and Medicaid Services as meeting the criteria for LVAD implantation, to date, only 175 HeartMate destination therapy implantations have been done since the REMATCH trial (personal communication on November 29, 2004, from Jerry Heatley, Manager, Clinical Data Systems, and Biostatistician, Thoratec Corporation, 23 Fourth Ave, Burlington, MA 01803; E-mail: jerry.heatley@thoratec.com). This low number of implantations is likely a reflection of the relatively high number of complications reported by the REMATCH investigators, most notably issues regarding device durability. ${ }^{1}$ Continued improvement in this and other ventricular assist device technologies will likely continue to decrease complications associated with device implantation and incidence of mechanical failure. However, until further improvements are implemented and demonstrated, cardiac transplantation remains the gold standard for the treatment of end-stage heart failure. ${ }^{4}$

Use of LVADs as destination therapy now offers an added dimension to caring for patients with severe end-stage heart failure who have relative contraindications to transplantation that might

TABLE 2. Hemodynamic parameters and serum creatinine level before and after LVAD implantation

\begin{tabular}{lccc}
\hline & $\begin{array}{c}\text { Mean (range) } \\
\text { PAP, mm Hg } \\
\text { (n = 5) }\end{array}$ & $\begin{array}{c}\text { Mean (range) } \\
\text { PVR, Wood } \\
\text { units }(\mathbf{n}=\mathbf{5})\end{array}$ & $\begin{array}{c}\text { Mean (range) } \\
\text { creatinine, mg/dL } \\
\text { (n = 2) }\end{array}$ \\
\hline Before LVAD & $46(41-50)$ & $5.5(2.5-12)$ & $2.8(2.7-2.9)$ \\
After LVAD & $23(12-30)$ & $2.1(0.9-3)$ & $1.15(0.8-1.5)$ \\
\hline
\end{tabular}

$\angle V A D$, Left ventricular assist device; $P A P$, pulmonary arterial pressure; $P V R$, pulmonary vascular resistance. potentially be remedied. In our patients the gradual improvement of significant pulmonary hypertension was seen in 5 patients after destination therapy. These improvements eventually allowed listing for cardiac transplantation, and 4 patients underwent successful transplantation. Improvement in pulmonary vascular resistance with LVAD support has been observed previously, and one possible explanation is that maximal unloading of the heart removes secondary pulmonary hypertension as a contributing factor. It is also possible that the unloading of the heart might have allowed for actual reverse remodeling of the pulmonary arteries, such as decreased medial hypertrophy over time.

The intent of this report is to emphasize the importance of continued reevaluation of LVAD destination therapy patients for significant improvement and reversal of relative contraindications that would allow for consideration for transplantation, especially as predictable device end-of-life approaches or complications, such as localized device infection, occur. This therapy might be particularly beneficial to patients with curable forms of cancer or those with pharmacologically irreversible pulmonary hypertension.

\section{References}

1. Rose EA, Gelijns AC, Moskowitz AJ, et al. Randomized Evaluation of Mechanical Assistance for the Treatment of Congestive Heart Failure (REMATCH) Study Group. Long-term mechanical left ventricular assistance for end-stage heart failure. N Engl J Med. 2001;345:1435-43.

2. Mehra MR, Uber PA, Uber WE, Ventura HO. Destination therapy in late-stage heart failure. Coron Artery Dis. 2004;15:87-90.

3. Van Nooten G. Medicare reimbursement for destination therapy. Artif Organs. 2004;28:526-8.

4. Hosenpud JD, Bennett LE, Keck BM, et al. The Registry of the International Society for Heart and Lung Transplantation: eighteenth official report-2001. J Heart Lung Transplant. 2001;20:805-15. 